Acta Theriologica 42 (1): 79-90, 1997.

PL ISSN 0001-7051

\title{
Spatial organization in a small population of the root vole Microtus oeconomus in a linear habitat
}

\author{
Jorun FAUSKE, Harry P. ANDREASSEN and Rolf A. IMS
}

\begin{abstract}
Fauske J., Andreassen H. P. and Ims R. A. 1997. Spatial organization in a small population of the root vole Microtus oeconomus in a linear habitat. Acta Theriologica 42: $79-90$

We studied demography and spatial organization in a population of root voles Microtus oeconomus (Pallas, 1776) inhabiting a fenced, linear habitat $(560 \times 1.5 \mathrm{~m})$ during the breeding season, using live trapping and radiotelemetry. There were no establishments of new reproductive individuals. Compared to root voles in non-linear habitats, home ranges were extremely small and no male home ranges overlapped. A short term removal and reintroduction experiment ( 2 days removal of every second individual on the study area) produced no changes in home range size, indicating that home range borders were not defended by daily contact between neighbours.

Division of Zoology, Department of Biology, University of Oslo, P. O. Box 1050 Blindern, N-0316 Oslo, Norway

Key words: Microtus oeconomus, linear habitats, intruder pressure, home range, spatial organization
\end{abstract}

\section{Introduction}

Landscapes, and in particular those affected by human action, are characterised by linear habitat structures. Fencerows, river and road banks, hedgerows, railwaylines, dikes, ditches, powerlines, and herbaceous and shrubby strips created specifically for wildlife management purposes are referred to as line corridors or habitat corridors (Forman and Godron 1986, Bennett 1990a). The ecological function of these linear habitats in landscapes has been of main consideration in environmental management (Bennett 1990a, Hobbs 1992), with the emphasis put on the role of linear habitats as dispersal corridors (Eldridge 1971, Wegner and Merriam 1979, Forman and Godron 1986, Bennett 1990b). However, linear habitat structures may contain potential resources for long-term survival and reproduction as well. Although several studies have indicated that linear habitats may be inhabited by several species (Pollard and Relton 1970, Eldridge 1971, Yahner 1983, Bennett 1990b), it is not known what characterises animal populations occupying linear habitats permanently. We here describe demography and spatial organization in a population of root voles Microtus oeconomus (Pallas, 1776) naturally established in a linear habitat. We also present the results from a preliminary 
study of linear habitats as experimental areas, where we performed a short term removal and reintroduction of every second female and male in the linear habitat. Given that daily contact between individuals were necessary to keep home range borders, our expectations were that animals would expand their home ranges when neighbours were removed and contract their home ranges when animals were reintroduced due to intruder pressure.

\section{Material and methods}

This study was carried out from July 31 to October 20, 1991 on a part of the experimental area at Evenstad Research Station in Hedmark County, SE Norway, named the E-grid (Fig. 1). The E-grid was enclosed by a wire-mesh fence extending $1.5 \mathrm{~m}$ above and $0.2 \mathrm{~m}$ under ground level, equipped with an electrical wire at the top to exclude all mammalian predators. The inner fence, consisting of a solid metal sheet extending $0.6 \mathrm{~m}$ above and $0.4 \mathrm{~m}$ under ground level and impossible for voles to penetrate, enclosed 7 study plots on the experimental area. The fenced area had been naturally colonised by root voles prior to this study. Owing to the wire-mesh fence root voles below $35 \mathrm{~g}$ could move freely through the fence. The area was probably colonised during the preceding winter or spring. The decision to use this setting as a basis for a scientific study was, however, not taken until the end of June when a preliminary live trapping session showed that the E-grid contained a resident population of root voles. Almost all females inhabiting the E-grid in June was observed with open pelvis indicating that they had given birth to at least one litter.

The final study plot, the E-grid, was enclosed by solid metal sheet fences on July 31 (see legend to Fig. 1). The E-grid area, now a narrow enclosed strip of habitat $(560 \times 1.5 \mathrm{~m})$, contained 15 mature females and 6 mature males which made up the study population. A vegetation analysis at the end of the study revealed that about half of the E-grid consisted of a varying, but scarce, vegetation cover of grass and herbs, whereas the other half consisted mainly of grass. A small area in the middle contained no vegetation owing to work with the fencing. No other microtine species were present on the E-grid.

Fifty-eight multiple capture live traps were evenly spaced along the study area (Fig. 1). Five trapping sessions were conducted after enclosure of the E-grid from July 31 until October 19, each

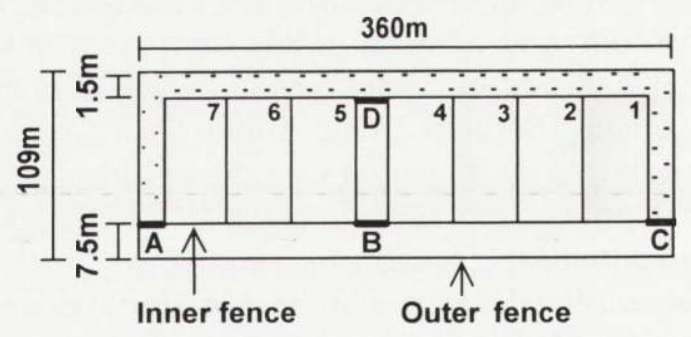

Fig. 1. A sketch of the experimental area of the Evenstad Research station, depicting the history of the E-grid. The outer fence is a wire mesh fence with electric wires on the top, while the inner fence surrounding the seven main experimental plots (nos 1-7), and fences A, B, C and D (thick lines) are made of solid steel sheets. Fences A, B and C were set up on June 25, while fence D was set up on July 31 . The small dots indicate positions of live traps in the E-grid, ie the study area used in the present study. 
Table 1. Study protocol of radiotracking and the removal and reintroduction experiment with root voles. FI and FII are two female groups (containing 5 females each), while MI and MII are two male groups (containing 3 and 2 males respectively). Removals and reintroductions were performed in the evening the days presented, just after the last tracking. 16. August was used as a basis to compare eventual changes in home range size due to removals. Eventual changes in home range size after reintroductions were compared to the home range size during removals.

\begin{tabular}{|c|c|c|c|c|c|}
\hline \multirow{2}{*}{$\begin{array}{l}\text { Manipulation } \\
\text { period }\end{array}$} & \multirow{2}{*}{ Date } & \multicolumn{2}{|c|}{ Number of animals tracked } & \multirow{2}{*}{$\begin{array}{l}\text { Number } \\
\text { of fixes }\end{array}$} & \multirow{2}{*}{ Removals } \\
\hline & & Females & Males & & \\
\hline
\end{tabular}

Premanipulation

$\begin{array}{lrrrr}\text { August } 14 & 9 & 3 & 7 & \\ \text { August } 16 & 10 & 5 & 7 & \text { FI removed }\end{array}$

Female manipulations

\begin{tabular}{|c|c|c|c|c|}
\hline August 18 & 5 & 5 & 7 & FI reintroduced \\
\hline August 19 & 10 & 5 & 7 & \\
\hline August 20 & 10 & 5 & 7 & FII removed \\
\hline August 21 & 5 & 5 & 7 & \\
\hline August 22 & 5 & 5 & 7 & FII reintroduced \\
\hline August 23 & 10 & 5 & 7 & \\
\hline August 24 & 10 & 5 & 7 & \\
\hline August 27 & 10 & 4 & 7 & \\
\hline \multicolumn{5}{|l|}{ ations } \\
\hline August 26 & & & & MI removed \\
\hline August 28 & 10 & 3 & 7 & MI reintroduced \\
\hline August 30 & 10 & 5 & 7 & MII removed \\
\hline September 1 & 10 & 2 & 7 & \\
\hline September 2 & 10 & 2 & 7 & \\
\hline September 3-8 & 0 & 2 & 16 & \\
\hline September 8 & & & & MII reintroduced \\
\hline September $9-14$ & 0 & 5 & 14 & \\
\hline
\end{tabular}

consisting of 5-9 trap checks. One trapping session was performed just outside the semipermeable fence at the end of the study period (October 18 and 19, two trap checks) to check whether young aninals marked inside the E-grid had established on the outside. Individual identification, sex, reproductive status and weight were monitored at each capture. We measured reproductive activity by registering pregnancies, and the success of delivered litters by the capture of juveniles (animals below $22 \mathrm{~g}$ ).

On August 12, the trapped animals (ie 9 and 3 reproductive active females and males, respectively) within the fenced area were equipped with radio-collars (Biotrack, England). The last 3 animals (a female and 2 males) were radiotagged on August 15. The animals were given two days to adjust to the transmitter before we started to track them on August 14 by positioning the animal with an omnidirectional antenna when walking outside the fence (see Andreassen et al. 1993). Radiotracking was performed by tracking all individuals every two hours from 09.00 in the morning till 21.03 in the evening. Each animal was positioned to the nearest $1.5 \mathrm{~m}$, and only the position of the animal along the longitude (ie only one coordinate axes) of the study area was monitored. See Table 1 and legend to Fig. 3 for tracking days and sample sizes. 


\section{The removal experiment}

During the removal experiment, 12 females and 5 males inhabited the study plot. However, due to death events (see below), and because one transmitter equipped on a female failed, the experimental study consisted of 10 females and 5 males.

The study procedure for the removal and reintroduction experiment is summarised in Table 1 . After a premanipulation period with two days of tracking, the population was divided into four groups based on the sequential position of females and males in the linear habitat (see also Fig. 3 and 4): FI - every second female living along the study plot, FII - the other half of the females, MI - every second male living along the study plot, MII - the remainder of the males.

The experimental procedure consisted then of a period of female manipulations were we first removed FI individuals for two days. The animals removed were kept in separate cages outside the study plot with surplus food and water supply. After an adjustment period of one day, the remaining animals were radio-tracked on the second day after the removal of FI. After terminating the radiotracking the second day at 21.00 hours FI females were reintroduced at the place they were removed two days earlier. Thereafter the population was allowed to readjust for one day followed by one day of radio-tracking with all animals present. The same experimental procedure as conducted for FI (removing and reintroducing) was then repeated for FII.

Male manipulations started on August 26 by the removal of MI males, whereafter we carried out the same procedure with the males as done for females (see Table 1 for study procedure). At the end of the study the MII group was not reintroduced. Rather, we continued to track the two males belonging to group MI 2-3 times a day for six days (September 3-8), to get an indication on how long time they eventually needed to respond to the removal of neighbours. Sixteen radiotracking observations randomly spread in time ( $2-3$ per day), but within 09.00 and 21.00 hours, were made this period. Likewise, we radiotracked the animals 14 times after reintroducing the MII males, during the period September 9-14.

\section{Analyses}

For a description of spatial organization of the population, home range sizes were estimated for three two-day periods (14 fixes) without any removals (August 14-16, 19-20, 23-24) as the longest distance between tracked positions multiplied by $1.5 \mathrm{~m}$ (ie the width of the study area). However, due to the small number of observations per day, and the short period of time ( 2 days) we also estimated home ranges for the total radiotracking period from August 14 until September 2 (whereafter the MII males were kept out of the study area, and only males were tracked; Table 1) for females and males (including periods of removals), and the total period prior to male removals (August 14-24) for males.

For the removal experiment we estimated daily home range sizes consisting of only one day (second day after removal/reintroduction) and thus only 7 observations, which are normally too few to get robust and unbiased estimates of home range size. However, as our estimates are based on space use in an one dimensional system rather than space use along two dimensions, we assumed that fewer observations than normal would be enough for a rough description of space use. While our estimates might be biased downwards, the increase in home range size when including fixes over several days (7-90 fixes) of monitoring was generally slow (Fig. 2). Further, as our estimates are to be used to compare daily home ranges monitored in the same manner only, very accurate estimates of home range sizes are not needed.

Statistical comparisons of daily home ranges before and after manipulations (removals/reintroductions) were performed by the use of bootstrapping techniques (Efron and Tibshirani 1993). Sampling distributions of daily space use estimates were obtained as follows: from the 7 fixes per day per individual we bootstrapped (drew by random and with replacement) a sample of size $7(n=7)$, and estimated the home range size and core areas for the bootstrapped sample. This procedure was repeated 100 times for each individual range. Mean home range size, mean core area, and their respective errors (95\% confidence intervals) were then estimated from the 100 simulated samples. An 
indlivitual's range was then assumed to have changed if $95 \%$ confidence intervals of two bootstrapped samples did not overlap.

\section{Results}

\section{Demographic background}

From an initial number of 15 mature females and 6 mature males in the E-grid, there was a steady decrease in the number of mature animals during the study period, leaving 8 mature females and 4 mature males in the last trapping period (Table 2). Two females died in a trap accident between trapping period 1 and 2 which explains the decrease from 15 to 13 , one radiocollared female was found dead between trapping periods 2 and 3 and one between periods 3 and 4 . There were no external signs of violence on any of the animals found dead.

Based on detected pregnancies we estimated that individual females gave birth to 1.7 litters (range: $1-3$ ) during the 81 days the study lasted. We captured and marked 28 juveniles in the same period. Only five of these were captured more than once, and no juvenile was ever captured in more than one trapping period

Table 2. Minimum number of alive root voles on the study plot in the 5 trapping periods.

\begin{tabular}{ccccc}
\hline $\begin{array}{c}\text { Trapping } \\
\text { period }\end{array}$ & $\begin{array}{c}\text { Trapping } \\
\text { date }\end{array}$ & $\begin{array}{c}\text { Mature } \\
\text { females }\end{array}$ & $\begin{array}{c}\text { Mature } \\
\text { males }\end{array}$ & Juveniles \\
\hline 1 & Jul 31 - Aug 3 & 15 & 6 & 4 \\
2 & Aug 11 - Aug 12 & 13 & 6 & 0 \\
3 & Aug 17 - Aug 22 & 12 & 5 & 8 \\
4 & Sep 18 - Sep 19 & 9 & 4 & 6 \\
5 & Oct 14 - Oct 19 & 8 & 4 & 10 \\
\hline
\end{tabular}

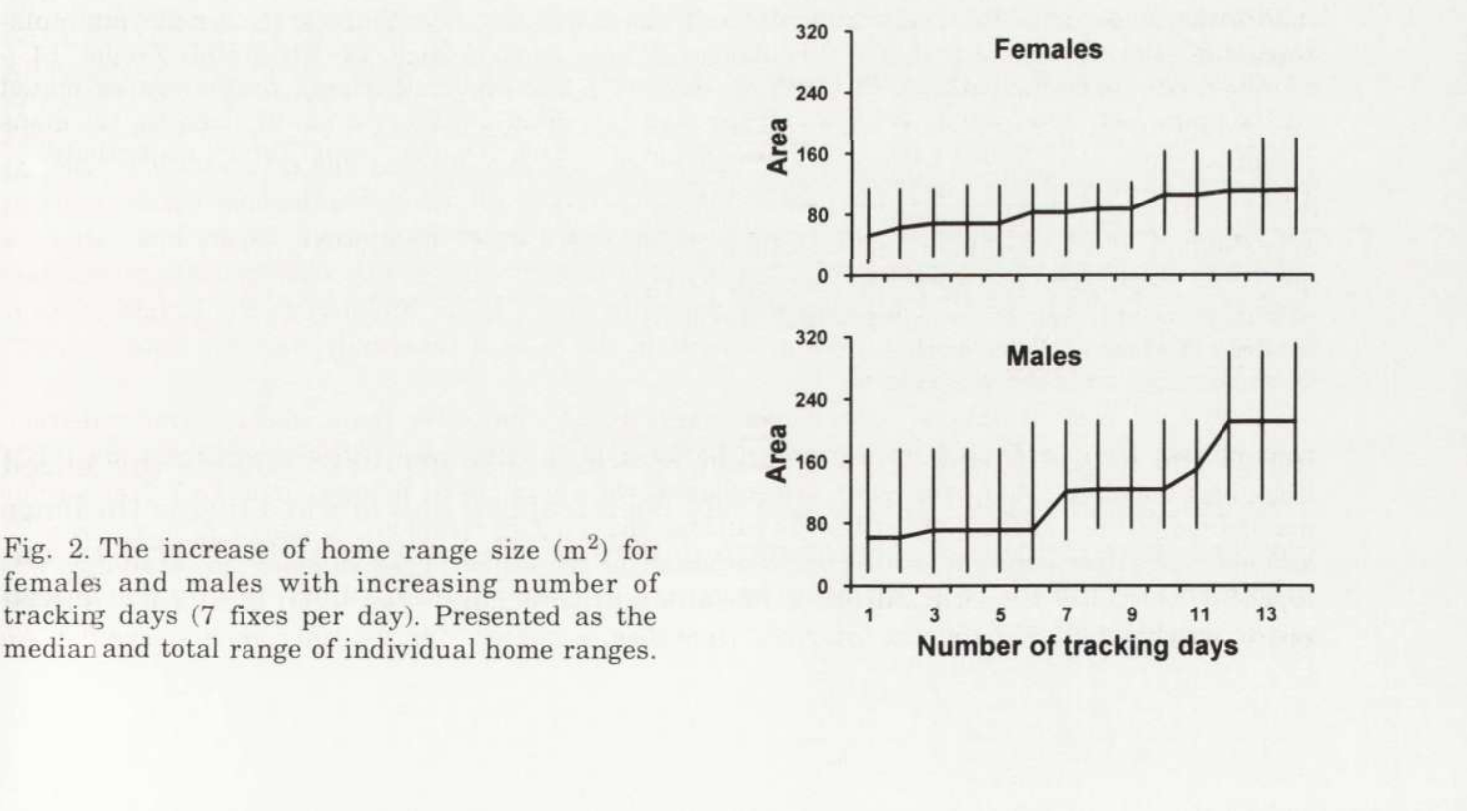




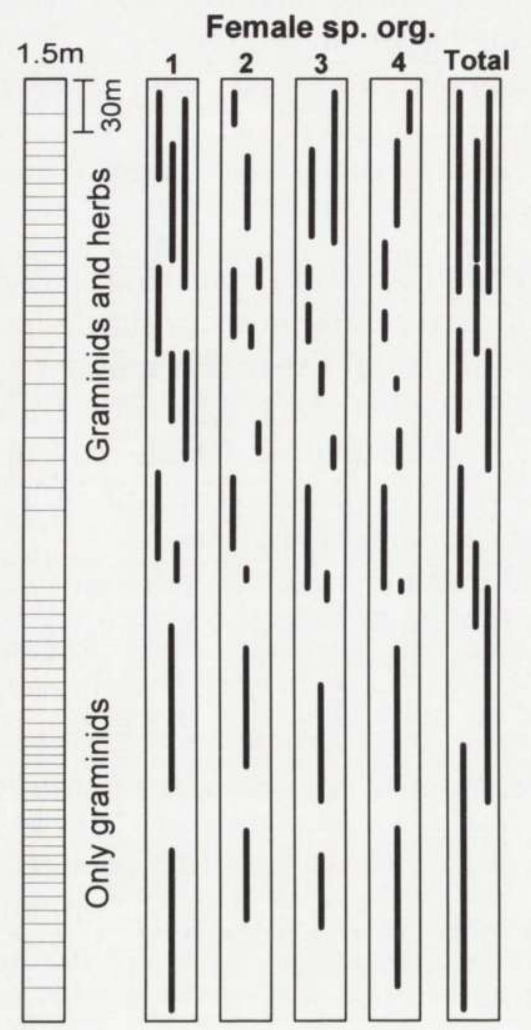

Fig. 3. Female spatial organization, presented by the length of female home ranges, for the following periods: (1) premanipulation, August 14-16; (2) after FI reintroduction, August 19-20; (3) after FII reintroduction, August 23-24; (4) during MI removal, August 27-28; (Total) August 14 - September 2. Home ranges are estimated from 14 fixes (two days) for the maps 1-4, and from 84-91 fixes for the map entitled "Total". The map to the left show composition and density of the vegetation cover. Vegetation density indicated by hachure density. A section in the middle of the E-grid with no vegetation separates two vegetation patterns: an area consisting only of graminids and an area consisting of a combination of graminids and herbs.

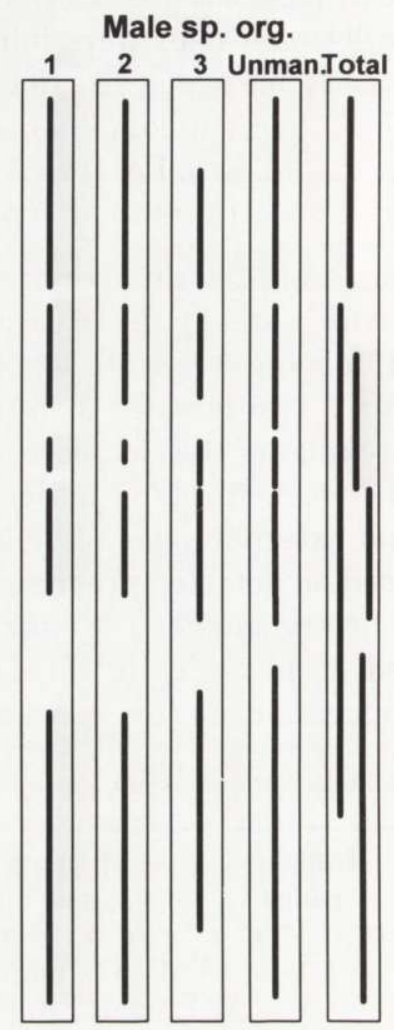

Fig. 4. Male spatial organization for the following periods: (1) premanipulation, August 14-16; (2) after FI reintroduction, August 19-20; (3) after FII reintroduction, August 23-24; (Unman.) prior to male manipulations, August 14-24; (Total) August 14 September 2. Home ranges are estimated from 14, 63 and 84-91 fixes for the maps 1-3, "Unman." and "Total", respectively.

inside the E-grid (Table 2). Three out of 8 juveniles captured outside the fenced area at the end of the study period had been trapped and marked inside the fence earlier. Hence, despite decreasing numbers of adults within the E-grid no immigration occurred from outside the fence, and no juveniles born inside the fenced area established there. 


\section{Spatial organization}

Home range sizes were fairly stable from August 14 till September 2. (Figs 2, 3 , and 4). Home range size in the premanipulation period (radiotracking on August 14 and 16) had a median of $62 \mathrm{~m}^{2}$ for both females (range: $23-114 \mathrm{~m}^{2}$ ) and males (range: $18-176 \mathrm{~m}^{2}$ ). For the period August 14 to September 2 home range estimates based on 77-91 observations per individual had a median of $113 \mathrm{~m}^{2}$ (range: $53-179 \mathrm{~m}^{2}$ ) and $210 \mathrm{~m}^{2}$ (range: $110-311 \mathrm{~m}^{2}$ ) for females and males, respectively. Prior to male manipulations (August 14 - August 24) male home ranges estimated from 56-63 fixes had a median of $123 \mathrm{~m}^{2}$ (range: 74-212 $\mathrm{m}^{2}$ ). All these home range estimates were much lower than any previously published home range estimate of reproductively active root voles (Table 3 ).

All females had some part of their home range overlapping at least one other female during the entire study period from August 14 - September 2 (see total in Fig. 3). However, for the two-day estimates of home range only 16 out of the 50 home ranges estimated overlapped another female home range. The number of overlapping females decreased from 8 prior to any manipulation to a maximum of 4 after the first removal (Fig. 3). No incidence of overlap between males was observed before the manipulation of male density (Fig. 4). When combining all radiotracking data from the period before male manipulation (56-63 observations), home range borders between males were contiguous, but did never overlap. In the period after the onset of male removals, there were some changes in home range size (see below). However, when combining all radiotracking data until September 2 still only one male, which had the smallest male home range before male removals had increased its home range, and thus overlapped 3 other males.

Table 3. Mean size $\left(\mathrm{m}^{2}\right)$ of female and male home ranges of root voles. Only the present study was conducted in a linear habitat. The home range sizes presented are: the medians (range) for the entire study period August 14 - September 2 for the present study, mean (range) for females and the minimum value for males presented in Tast (1966), and mean $( \pm \mathrm{SE})$ for the other studies. Tast (1966) estimated home range size from trapping data by the use of the boundary strip method (Stickel 1954). All other studies have used radiotelemetry to estimate the home ranges, Ims et al. (1993) by the use of the 95\% multinuclear probability polygon (Kenward 1987), all other studies by the use of outer convex polygon. * Ims et al. (1993) presented home range sizes for two different strains of root voles (A and B). $n$-sample size.

\begin{tabular}{|c|c|c|c|c|c|}
\hline \multicolumn{2}{|c|}{ Females } & \multicolumn{2}{|c|}{ Males } & \multirow{2}{*}{$\begin{array}{l}\text { Number } \\
\text { of fixes }\end{array}$} & \multirow{2}{*}{ Source } \\
\hline$n$ & Home range & $n$ & Home range & & \\
\hline 21 & $530(200-1000)$ & 4 & $>800$ & $<15$ & Tast 1966 \\
\hline 12 & $1087( \pm 327)$ & 3 & $3896( \pm 2044)$ & 19 & Lambin 1992 \\
\hline 7 & $478( \pm 198)$ & 10 & $426( \pm 198)$ & 25 & Ims et al. $1993^{*}$ \\
\hline 9 & $276( \pm 58)$ & 9 & $546( \pm 60)$ & 25 & I \\
\hline 13 & $706( \pm 119)$ & 4 & $730( \pm 293)$ & $\sim 100$ & Eliassen 1996 \\
\hline 21 & $377( \pm 50)$ & 25 & $804( \pm 117)$ & 25 & Gliwicz, in press \\
\hline 10 & $113(53-179)$ & 5 & $210(110-311)$ & 86 & Present study \\
\hline
\end{tabular}


The vegetation cover was spatially variable, which probably caused a significant preference among females for the area containing both graminids and herbs compared with the area with just graminids (binominal test under the null hypothesis that females were distributed independently of vegetation cover, $p=0.02$ ), and only two females were resident on the part of the E-grid containing mainly graminids. It was also these two females that usually had the two largest daily home ranges (Fig. 3).

\section{Removal experiment}

The stability of daily home ranges was checked by comparing the size distributions (generated by bootstrapping) of individual home ranges at August 14 and August 16 (ie before any removal). Of the 9 females and 3 males radiotracked during these two days (see Table 1 ) one female and one male ( $16 \%$ of the total animals tracked) changed their home range size. Hence, a certain, but probably small, proportion of home ranges showed a normal fluctuation in size from day to day in this system.

During each of the two female removal periods, 1 out of the 5 remaining females (a total of 2 out of 10 comparisons) decreased her home range size significantly compared to the daily home range size before manipulations (August 16). After reintroducing the females, 1 out of 5 (FII females) increased and 1 out of 5 (FI) decreased her daily home range size significantly compared to the period when they were alone (August 18 and 22, respectively). Thus, in total females changed their home range size in 4 out of 20 comparisons $(20 \%)$, which is not different from what was found in the premanipulation period $\left(\chi^{2}=0.01\right)$. In only one out of the 4 occasions of home range change a female changed her home range in accordance with our expectations; ie decreased after reintroduction of neighbouring females, whereas 3 females changed their home ranges counter to our expectations; either by expanding their home range after reintroduction of neighbours, or decreasing their home ranges after removal of neighbours.

After the first removal of males (removal of MI), 1 out of 3 remaining males (MII males) increased his home range size significantly compared to the daily home range size before manipulations (August 16), but none of the 3 MII males changed their daily home range size significantly after reintroduction of MI (August 28). After the second removal of males, 1 out of the 2 remaining males (MI males) increased his home range size significantly compared to the daily home range size before manipulations (August 16). As MI males were kept out and not reintroduced until September 9, both MII males increased their home range size significantly during the period from September 3 to September 8, compared to before manipulations (August 16). MII males were first reintroduced on September 9 (removed for 10 days). After reintroducing MII males, 1 out of the 2 MI males decreased daily home range size significantly compared to when MI males were alone (September 3-8). 
Thus, in total males changed their ranges in $2(25 \%)$ out of 8 comparisons made with respect to the two days removals/reintroductions. This was not different from the total number of changes occurring in equivalent premanipulation comparisons $\left(\chi^{2}=0.05\right)$. The two changes occurring were, however, consistent with our expectations. The two males subject to a long term removal of neighbours, both increased their home ranges as expected, and one decreased as expected after reintroductions.

\section{Discussion}

We have studied a naturally established population of root voles inhabiting a fenced, linear area. Despite the fencing we think our system resembles natural linear, hard edged (sensu Stamps et al. 1987) root vole habitats. Root voles are commonly found in strips of river-side vegetation, road banks and along ditches (Tast 1966, 1968). In fact among the microtines, the root vole may be one of the species most adapted to live in linear habitats. Our study population was reproducing and all females gave birth to at least one litter during the study period. The reproductive success was difficult to estimate in this study, because juveniles probably escaped through the fence before being trapped, and because our removal manipulation certainly interfered with reproduction during the latter half of August. Among the juveniles that were captured and marked within the E-grid, none established themselves as reproductive adults there, but probably dispersed through the semipermeable wire fence to areas outside the grid. Moreover, there was no recruitment from areas outside the fence.

The monitoring of space use of individual root voles in the linear habitat yielded two interesting results. First, both male and female home range size were dramatically smaller (approximately an order of magnitude) than what has been observed for root voles in non-linear habitats, even though the present study contained many more observations per individual than other published studies on root vole home range (see Table 3). The shape of the environment may have important implications for the costs associated with resource acquisitions. For a given resource density, living in a linear habitat involves longer movements per food item than when movements in several directions are possible. Other possible mechanisms underlying the extremely small home range sizes observed in this study may be related to the social interaction that are specific to linear habitats. This latter possibility is related to our second main result from the space use analyses, the low degree of male home range overlap.

Male root voles usually show some degree of intrasexual overlap in home ranges (Tast 1966, Lambin et al. 1992, Ims et al. 1993). The totally exclusive home ranges among males before male removals observed by us in the linear habitat indicate that territoriality (degree of exclusive use of space, sensu Pitelka 1959) may be more pronounced in this linear situation. Territoriality may, in terms of cost-benefit consideration, be more feasible in a linear than in a non-linear habitat, 
since the defenceability of a home range within a linear habitat may be higher. Two important determinants of home range defenceability will be lower than in a spacing system with a higher interior to edge ratio: the number of neighbours and the total length of border lines between neighbouring territories. This should decrease the territory threshold (Carpenter and McMillan 1976) in a linear habitat.

For birds, which maintain territory borders by vocalisation and direct confrontations, it has been shown by means of short-term removal experiments that territory borders are dynamic with respect to intruder pressure (eg Newton 1992 and references therein). Here, home ranges were exceptionally stable even when increasing sample size from 7 to 90 observations, over a period of 20 days, and despite continuous disturbance of the population by removals. The small sample sizes and the short term removal of the removal/reintroduction experiment do not permit firm conclusions. The few and moderate space-use changes observed do not support the hypothesis that territory borders are maintained by frequent direct interactions (eg aggressive defence) in root voles. However, home ranges were exceptional stable which may indicate that animals were observed at their home range borders daily. Although removal experiments of this kind have rarely been done for mammals, some other studies have reached similar conclusions, ie that there is a low degree of direct confrontations on home range borders. McShea (1990) showed that male meadow voles Microtus pennsylvanicus increased their home ranges within $24 \mathrm{~h}$ of removal of nestmates, whereas females did not. Price et al. (1986) and Klenner (1991) did not observe expansion of territories in squirrels subject to removal of neighbours (see also Larsen and Boutin 1995). Finally, a study on foxes (White and Harris 1994) indicated that direct encounters were relatively unimportant in territory defence. Thus, intruder pressure may not have the same immediate effect on home range size for mammals as for birds.

\section{Conclusion}

The two most marked attributes observed in our linear root vole population were the small home range sizes and the absolute emigration of young individuals. Given the increasing importance of linear habitats in conservation of wildlife especially in urban and agricultural landscapes, we believe that our results may have bearing on the question whether corridors functions as links or sinks in such landscapes. Our results must be considered as preliminary and further studies are needed. In addition to the importance of linear habitats to conservation of populations, our study demonstrates the applicability of linear habitats as useful experimental model systems for exploring mechanisms underlying the spacing of individuals in a population.

Acknowledgements: We are grateful to S. Evans for contributing substantially during the entire field work and thereby making this study possible. J. Aars, T. Agustsson, K. W. Berg, O. Bjørnstad and T. Hansteen contributed with goodwill and field assistance. This study was supported financially by the Norwegian Research Council for Science and the Humanities (NFR), and is a contribution to the project "Habitat fragmentation: implications for the dynamics of populations". 


\section{References}

Andreassen H. P., Ims R. A., Stenseth N. C. and Yoccoz N. 1993. Investigating space use by means of radiotelemetry and other methods: a methodological guide. [In: Biology of lemmings. N. C. Stenseth and R. A. Ims, eds]. Academic Press, London: 589-618.

Bennett A. F. 1990a. Habitat corridors: Their role in wildlife management and conservation. Department of Conservation and Environment, Melbourne, Australia: 1-36.

Bennett A. F. 1990b. Habitat corridors and the conservation of small mammals in fragmented forest environment. Landscape Ecology 4: 109-122.

Carpenter F. L. and McMillan R. E. 1976. Threshold model for feeding territoriality and test with a Hawaiian honey-creeper. Science 194: 639-642.

Efron B. and Tibshirani R. J. 1993. An introduction to the bootstrap. Monographs on statistics and applied probability 57. Chapman and Hall, London: 1-436.

Eldridge J. 1971. Some observations on the dispersion of small mammals in hedgerows. Journal of Zoology, London 165: 530-534.

Eliassen K. 1996. Resource utilization in small rodents: Space use in root voles (Microtus oeconomus Pallas) and food discrimination in Norwegian lemmings (Lemmus lemmus L.). Cand. Scient. thesis, University of Bergen, Norway: 1-47.

Forman R. T. T. and Godron M. 1986. Landscape ecology. J. Wiley and Sons, New York: 1-619.

Gliwicz J. 1997. Space use in the root vole: basic patterns and variability. Ecography (in press).

Hobbs R. J. 1992. The role of corridors in conservation: solution or bandwagon. Trends in Ecology and Evolution 7: 389-392.

Ims R. A., Rolstad J. and Wegge P. 1993. Predicting space use responses to habitat fragmentation: can voles Microtus oeconomus serve as an experimental model system (EMS) for capercaillie grouse Tetrao urogallus in boreal forest? Conservation Biology 63: 261-268.

Kenward R. 1987. Wildlife radio tagging. Equipment, field techniques and data analyses. Academic Press, London: 1-222.

Klenner W. 1991. Red squirrel population dynamics. II. Settlement patterns and the response to removals. Journal of Animal Ecology 60: 979-993.

Lambin X., Krebs C. J. and Scott B. 1992. Spacing system of the tundra vole (Microtus oeconomus) during the breeding season in Canada's Western Arctic. Canadian Journal of Zoology 70: 2068-2072.

Larsen K. W. and Boutin S. 1995. Exploring territory quality in the North American red squirrel through removal experiments. Canadian Journal of Zoology 73: 1115-1122.

McShea W. J. 1990. Social tolerance and proximate mechanisms of dispersal among winter groups of meadow voles, Microtus pennsylvanicus. Animal Behaviour 39: 346-351.

Newton I. 1992. Experiments on the limitations of bird numbers by territorial behavior. Biological Review 67: 129-173.

Pitelka F. A. 1959. Numbers, breeding schedule, and territoriality in pectorial sandpipers of northern Alaska. Condor 61: 233-262.

Pollard E. and Relton J. 1970. Hedges. V. A study of small mammals in hedges and cultivated fields. Journal of Applied Ecology 7: 549-557.

Price K., Broughton K., Boutin S. and Sinclair A. R. E. 1986. Territory size and ownership in red squirrels: response to removals. Canadian Journal of Zoology 64: 1144-1147.

Stamps J. A., Buechener M. and Krishnan V. V. 1987. The effects of habitat geometry or territorial defense costs: Intruder pressure in bounded habitats. American Zoologist 27: 307-325.

Stickel L. F. 1954. A comparison of certain methods of measuring ranges of small mammals. Journal of Mammalogy 35: 1-15.

Tast J. 1966. The root vole, Microtus oeconomus (Pallas) as an inhabitant of seasonally flooded land. Annales Zoologici Fennici 3: 127-171. 
Tast J. 1968. The root vole Microtus oeconomus (Pallas), in man-made habitats in Finland. Annales Zoologici Fennici 5: 230-240.

Wegner J. F. and Merriam G. 1979. Movements by birds and small mammals between a wood and adjoining farmland habitat. Journal of Applied Ecology 16: 349-357.

White P. C. L. and Harris S. 1994. Encounters between red foxes (Vulpes vulpes): implications for territory maintenance, social cohesion and dispersal. Journal of Animal Ecology 63: 315-327.

Yahner R. H. 1983. Small mammals in farmstead shelterbelts: habitat correlates of seasonal abundance and community structure. Journal of Wildlife Management 47: 74-84.

Received 22 May 1995, resubmitted revised version 26 August 1996, accepted 15 January 1997. 